\title{
Mobile App for Improved Self-Management of Type 2 Diabetes: Multicenter Pragmatic Randomized Controlled Trial
}

Payal Agarwal ${ }^{1,2}$, MD; Geetha Mukerji ${ }^{1,3,4}$, MSc, MD; Laura Desveaux ${ }^{1,4,5}$, PhD; Noah M Ivers ${ }^{1,2,4,5}$, MD, PhD; Onil Bhattacharyya $^{1,2,5}$, MD, PhD; Jennifer M Hensel ${ }^{1,5,6,7}$, MD, MSc; James Shaw ${ }^{1,5}$, PhD; Zachary Bouck ${ }^{1}$, MPH; Trevor Jamieson $^{1,3,8}$, MBI, MD; Nike Onabajo ${ }^{1}$, MSc; Madeline Cooper ${ }^{1}$, BAH; Husayn Marani ${ }^{4}$, MSc; Lianne Jeffs ${ }^{9}$, RN, PhD, FAAN; R Sacha Bhatia ${ }^{1,3,5}$, MBA, MD

\footnotetext{
${ }^{1}$ Women's College Hospital Institute for Health System Solutions and Virtual Care, Women's College Hospital, Toronto, ON, Canada

${ }^{2}$ Department of Family and Community Medicine, University of Toronto, Toronto, ON, Canada

${ }^{3}$ Department of Medicine, University of Toronto, Toronto, ON, Canada

${ }^{4}$ Institute for Health Policy, Management and Evaluation, University of Toronto, Toronto, ON, Canada

${ }^{5}$ Women's College Research Institute, Women's College Hospital, Toronto, ON, Canada

${ }^{6}$ Department of Psychiatry, University of Manitoba, Winnipeg, MB, Canada

${ }^{7}$ Department of Psychiatry, University of Toronto, Toronto, ON, Canada

${ }^{8}$ Division of General Internal Medicine, St Michael's Hospital, Toronto, ON, Canada

${ }^{9}$ Li Ka Shing Knowledge Institute, St. Michael's Hospital, Toronto, ON, Canada
}

\section{Corresponding Author:}

Payal Agarwal, MD

Women's College Hospital Institute for Health System Solutions and Virtual Care

Women's College Hospital

76 Grenville Street

Toronto, ON, M5S 1B2

Canada

Phone: 14163236400

Email: payal.agarwal@wchospital.ca

\section{Abstract}

Background: As the increasing prevalence of type 2 diabetes mellitus has put pressure on health systems to appropriately manage these patients, there have been a growing number of mobile apps designed to improve the self-management of diabetes. One such app, BlueStar, has been shown to significantly reduce hemoglobin $\mathrm{A}_{1 \mathrm{c}}\left(\mathrm{HbA}_{1 \mathrm{c}}\right)$ levels in small studies and is the first app in the United States to receive Food and Drug Administration approval as a mobile prescription therapy. However, the impact of the app across real-world population among different clinical sites and health systems remains unclear.

Objective: The primary objective of this study was to conduct a pragmatic randomized controlled trial of the BlueStar mobile app to determine if app usage leads to improved $\mathrm{HbA}_{1 \mathrm{c}}$ levels among diverse participants in real-life clinical contexts. We hypothesized that this mobile app would improve self-management and $\mathrm{HbA}_{1 \mathrm{c}}$ levels compared with controls.

Methods: The study consisted of a multicenter pragmatic randomized controlled trial. Overall, 110 participants randomized to the immediate treatment group (ITG) received the intervention for 6 months, and 113 participants randomized to the wait-list control (WLC) group received usual care for the first 3 months and then received the intervention for 3 months. The primary outcome was glucose control measured by $\mathrm{HbA}_{1 \mathrm{c}}$ levels at 3 months. Secondary outcomes assessed intervention impact on patient self-management, experience of care, and self-reported health utilization using validated scales, including the Problem Areas in Diabetes, the Summary of Diabetes Self-Care Activities, and the EuroQol-5D. Intervention usage data were collected directly from the app.

Results: The results of an analysis of covariance controlling for baseline $\mathrm{HbA}_{1 \mathrm{c}}$ levels did not show evidence of intervention impact on $\mathrm{HbA}_{1 \mathrm{c}}$ levels at 3 months (mean difference [ITG-WLC] $-0.42,95 \% \mathrm{CI}-1.05$ to $0.21 ; P=.19$ ). Similarly, there was no intervention effect on secondary outcomes measuring diabetes self-efficacy, quality of life, and health care utilization behaviors. An exploratory analysis of 57 ITG participants investigating the impact of app usage on $\mathrm{HbA}_{1 \mathrm{c}}$ levels showed that each additional 
day of app use corresponded with a 0.016-point decrease in participants' 3-month $\mathrm{HbA}_{1 \mathrm{c}}$ levels (95\% CI -0.03 to -0.003). App usage varied significantly by site, as participants from 1 site logged in to the app a median of 36 days over 14 weeks (interquartile range [IQR] 10.5-124); those at another site used the app significantly less (median 9; IQR 6-51).

Conclusions: The results showed no difference between intervention and control arms for the primary clinical outcome of glycemic control measured by $\mathrm{HbA}_{1 \mathrm{c}}$ levels. Although there was low usage of the app among participants, results indicate contextual factors, particularly site, had a significant impact on overall usage. Future research into the patient and site-specific factors that increase app utilization are needed.

Trial Registration: Clinicaltrials.gov NCT02813343; https://clinicaltrials.gov/ct2/show/NCT02813343 (Archived by WebCite at https://clinicaltrials.gov/ct2/show/NCT02813343)

(JMIR Mhealth Uhealth 2019;7(1):e10321) doi: 10.2196/10321

\section{KEYWORDS}

mobile apps; diabetes mellitus, type 2; self-management; blood glucose self-monitoring; randomized controlled trial; pragmatic clinical trial

\section{Introduction}

The worldwide burden of type 2 diabetes mellitus (T2DM) continues to increase, with almost $9 \%$ of the global population expected to have T2DM by 2035 [1]. The increasing prevalence of T2DM will put pressure on health systems to appropriately manage these patients to avoid diabetic complications. Optimizing self-management of glycemic control and other risk factors in conjunction with pharmacologic therapy may be an efficient way to improve patient outcomes [2-5]. Although self-management is traditionally offered through in-person educational programs, this is resource intensive, and advances in mobile technology provide the opportunity to deliver effective self-management support to patients that is convenient and potentially cost-effective [6-9].

There are a growing number of mobile apps designed to improve the self-management of T2DM patients [10-12], although few have been rigorously evaluated. One diabetes management app, called BlueStar, a smartphone-enabled app that is designed to serve as a virtual coach for patients, has been shown to significantly reduce hemoglobin $\mathrm{A}_{1 \mathrm{c}}\left(\mathrm{HbA}_{1 \mathrm{c}}\right)$ levels in T2DM patients, seen by primary care physicians [13]. As a result, BlueStar is the first app in the United States to be given Food and Drug Administration approval as a mobile prescription therapy [14]. Previous studies using BlueStar were small however and conducted on a relatively homogenous patient population [13]. As a result, it remains unknown whether the result of these studies would be generalizable to a diverse real-world population across different clinical sites. In addition, multiple studies of mobile apps for chronic diseases have highlighted the importance of contextual and implementation factors, including clinician training, integration into existing workflows, and ongoing clinician engagement with the patient as important influencers of clinical outcomes [15], yet previous studies were not designed to assess these factors.

The purpose of this study was to conduct a pragmatic randomized controlled trial of the BlueStar mobile app on T2DM patients with poorly controlled blood sugar to determine if the use of the app would lead to improved $\mathrm{HbA}_{1 \mathrm{c}}$ levels compared with controls in real-life clinical contexts. We hypothesized that this mobile app would improve patient self-management, and ultimately, patients with the app would have improved $\mathrm{HbA}_{1 \mathrm{c}}$ levels compared with controls.

\section{Methods}

\section{Settings}

Participants were recruited from 3 hospital-based diabetes education programs (DEPs) in Ontario, Canada. Most health services in Ontario, Canada, are financed through the publicly funded Ontario Health Insurance Program (OHIP), which covers medically necessary services delivered by physicians, including primary, specialty, and emergency care. Patients with T2DM typically get most of their diabetes care in short visits from family physicians who may or may not have additional multidisciplinary support. In addition, OHIP covers services provided by DEPs, which are multidisciplinary, nonphysician -led programs designed to deliver self-management education of diabetes and self-management support [16]. The 3 recruitment sites included (1) a DEP located in an urban area in a large city center ( $>2$ million people), (2) 1 located in a midsize city in a remote area of the province ( $<150,000$ people), and (3) 1 located in a semiurban area surrounding a large city center $(<600,000$ people). These sites serve a diverse range of patients including a large immigrant community, rural patients, and a large Aboriginal population. The services of these programs are complementary to primary care delivered through the patients' primary care provider (PCP) and usually do not include medication titration.

\section{Trial Design}

The study consisted of a multicenter, pragmatic randomized controlled trial with blinded outcome assessment designed to evaluate the effectiveness of the BlueStar app. A full description of the protocol has been previously published [17]. Participants with an $\mathrm{HbA}_{1 \mathrm{c}}$ level higher than $8.0 \%$ were recruited from the 3 DEPs, where they received support for diabetes management and randomized in a ratio of 1:1 to 2 groups: (1) immediate treatment group (ITG) or (2) wait-list control (WLC) group. The ITG received the intervention immediately for a total duration of 6 months. The WLC group received usual care for the first 3 months, at which point they received the intervention 
and used the app for a total of 3 months. Outcomes were measured at baseline as well as 3 and 6 months.

\section{Participants}

Participants were eligible for inclusion in the study if they met the following criteria: (1) adults aged older than 18 years; (2) obtaining care for T2DM at a participating DEP; (3) $\mathrm{HbA}_{1 \mathrm{c}}$ $\geq 8.0 \%$ (and at least $1 \%$ above the participant's target level) on most recent laboratory report within the last 3 months; (4) currently using an active email address or able and willing to obtain one; and (5) able to read the English language (self-reported). Patients were excluded if they have type 1 diabetes, were on continuous glucose monitoring, had an insulin pump, were on dialysis, pregnant, or are unable to use a computer or mobile phone because of severe mental or physical impairment.

\section{Recruitment Process}

Potential participants were identified by a clinician at each site during their regular scheduled appointments at a participating DEP. Those wanting more information met with the site coordinator and were given a brochure on the intervention and a copy of study consent form to review. If interested, the site coordinator would facilitate a phone call between the participant and study research assistant to obtain verbal consent. Participants were then randomized to 1 of 2 arms. Baseline questionnaires were completed over the phone by the research assistant at that time or within 2 weeks of randomization. Patients randomized to the ITG would meet with the site coordinator to receive the phone loaded with the BlueStar app along with a training session designed by the Ontario Telemedicine Network. Participants in the WLC group would arrange an appointment with the site coordinator in 3 months to receive their intervention and training.

\begin{abstract}
Allocation
Randomization was done in a centralized fashion by the Applied Health Research Centre (AHRC) at the Li Ka Shing Knowledge Institute of St. Michael's Hospital in Toronto, Canada. Subject randomization was computer generated and stratified by site, using block sizes of 2 or 4, through REDCap [18], a Web-based electronic data entry system at the AHRC. Once the participant completed a baseline questionnaire, the centralized research assistant accessed the randomization sequence and informed the patient of their allocation to receive 1 of 2 treatments with a 1:1 randomization scheme (ITG or WLC).
\end{abstract}

\section{Intervention}

The intervention was the BlueStar mobile app, designed to act as a virtual coach for patients with T2DM. The app was preloaded onto a cellular network-connected Samsung smartphone (with all other features disabled). The phone was connected to a cellular data plan for internet connectivity and was able to connect to local Wi-Fi networks. If participants used the app without an internet connection, the information was saved and uploaded to the secure server when the phone regained an internet connection. Patients could enter information related to T2DM management into the app, including baseline health, daily blood glucose readings, exercise activity, and food intake (see Multimedia Appendix 1). The app used this information to deliver customized, evidence-based messages in real time that aim to impact motivation, behavior, and education. The messages, based on the Transtheoretical Model of Behavior Change, included educational and affirmational content to encourage sustained behavior changes. Educational messages were aligned with the American Association of Diabetes Educators 7 Standard of Care [19]. The app also facilitated the transfer of data to the user's clinician through Smart Visit reports that provide a clinical overview of current diabetes management including recent blood sugar readings.

Patients in the WLC group received usual diabetes care by the DEP and their primary care physician for the first 3 months of the study. To align with the principles of pragmatic trials, the usual care received was not standardized among participants [20].

\section{Outcomes and Data Collection}

The primary outcome for the trial was glucose control measured by $\mathrm{HbA}_{1 \mathrm{c}}$ levels at 3 months. Secondary outcomes assessed intervention impact on patient self-management, experience of care, and self-reported health utilization using patient-reported outcomes measures and patient-reported experience measures. This included patient self-efficacy measured using 2 validated scales for diabetes, the Problem Areas in Diabetes [21] and the Summary of Diabetes Self-Care Activities [22], as well as quality of life measures using the EuroQol-5D (EQ-5D) [23].

Data were collected centrally by research assistants and inputted into the REDCap database. All outcomes were assessed at 3 and 6 months. Intervention usability, an additional secondary outcome, was evaluated by an adapted version of the Mobile App Rating Scale. App utilization data were routinely collected through the app. Utilization measures include the mean number of engagements per week and the frequency of use of each feature per week.

\section{Statistical Analysis}

Patient characteristics and baseline $\mathrm{HbA}_{1 \mathrm{c}}$ levels were summarized using descriptive statistics, including means and $\mathrm{SD}$ for continuous variables and proportions for categorical variables. Data were analyzed according to the intention-to-treat principle. Primary analyses used analysis of covariance (ANCOVA) with all complete cases. A secondary analysis adjusting for study site, length of diabetes diagnosis, ethnicity, and length in DEP was also conducted. A sensitivity analysis to explore the impact of missing data was conducted by identifying all characteristics that significantly differed between those included and not included and then adding these to the primary model with the assumption that the data are at least missing at random. Self-reported health utilization data including hypoglycemic episodes, visits to a primary care physician, visits to a specialist, visits to the emergency department, and hospital admission were converted to binary outcomes (event vs no event) and analyzed using a logistic regression model.

After 6 months, $\mathrm{HbA}_{1 \mathrm{c}}$ levels among those participants in the ITG were compared using a paired $t$ test to look for sustained impact of the intervention. App utilization data were analyzed 
descriptively, including frequency of use (mean uses per week) by site and feature. An exploratory analysis to assess the impact of app usage on 3-month $\mathrm{HbA}_{1 \mathrm{c}}$ and Problem Areas in Diabetes (PAID) scale values was conducted using general linear models that controlled for baseline values.

Power was determined assuming an ANCOVA analysis with an estimate correlation between baseline and follow-up $\mathrm{HbA}_{1 \mathrm{c}}$ measurements of 0.80 . The power to detect a difference of $0.7 \%$ in $\mathrm{HbA}_{1 \mathrm{c}}$ levels using an $\mathrm{SD}$ of $2 \%$ between treatment groups at 3 months is $99.7 \%$ at a significance level of $5 \%$, based on a sample size of 255 (which assumes a dropout rate of $15 \%$ from the target sample size of 300 participants).

\section{Results}

\section{Study Participants}

Potential participants were identified based on the study criteria and enrolled in the study between June and December 2016.
We invited 463 patients; of those, 145 were not interested, 74 were unreachable for follow-up, and 5 did not complete baseline questionnaires (Figure 1). Randomization was completed on 240 participants, but 17 were excluded ( 8 in the WLC group and 9 in ITG) because of an eligibility $\mathrm{HbA}_{1 \mathrm{c}}<8.0 \%$. Thus, 223 participants were included in the study. On follow-up, $77.1 \%$ $(172 / 223)$ of participants completed a baseline $\mathrm{HbA}_{1 \mathrm{c}}$ value, whereas $65.5 \%(146 / 223)$ completed the primary outcome $\left(\mathrm{HbA}_{1 \mathrm{c}}\right.$ levels at 3 months). A comparison of baseline characteristics shows no significant differences among those who completed the primary outcome versus those who did not, except that nonwhite were less likely to have a 3-month $\mathrm{HbA}_{1 \mathrm{c}}$ value (Multimedia Appendix 2). In total, 120 participants (63 in the WLC group and 57 in the ITG) had both baseline and 3-month $\mathrm{HbA}_{1 \mathrm{c}}$ values completed. 
Figure 1. Flowchart of enrollment. $\mathrm{HbA}_{1 \mathrm{c}}$ : hemoglobin $\mathrm{A}_{1 \mathrm{c}}$.

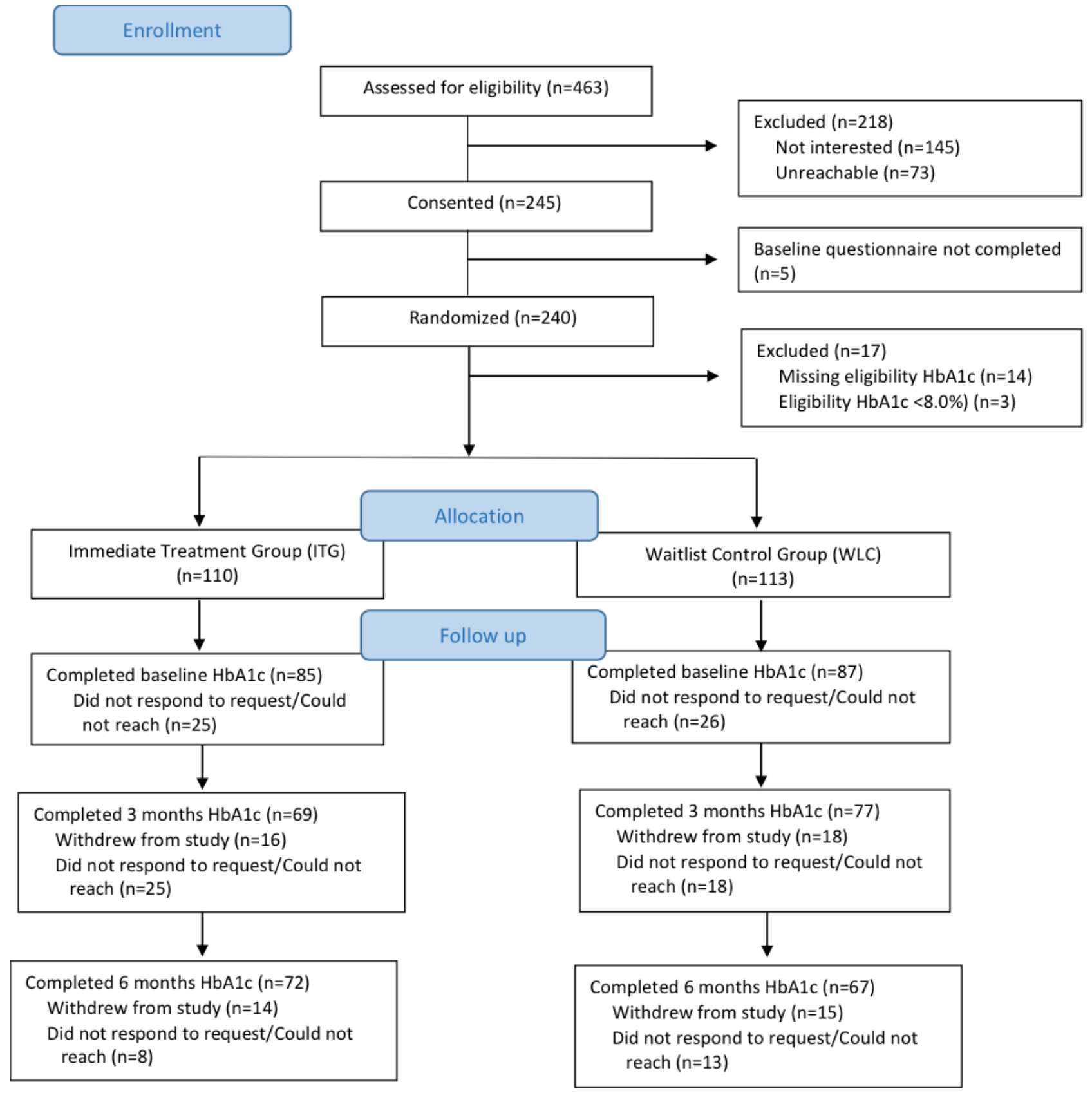


Table 1. Baseline characteristics of participants.

\begin{tabular}{|c|c|c|c|}
\hline Variable & Immediate treatment group $(\mathrm{n}=110), \mathrm{n}(\%)$ & Wait-list control $(\mathrm{n}=113), \mathrm{n}(\%)$ & Overall $(\mathrm{N}=223), \mathrm{n}(\%)$ \\
\hline Age $^{\mathrm{a}}$ (years), mean (SD) & $51.5(10.6)$ & $52.1(10.7)$ & $51.8(10.7)$ \\
\hline \multicolumn{4}{|l|}{ Sex, n $(\%)$} \\
\hline Male & $61(55.0)$ & $55(49.0)$ & $116(52.0)$ \\
\hline Female & $48(44.0)$ & $58(51.0)$ & $106(48.0)$ \\
\hline Not specified & $1(0.9)$ & $0(0.0)$ & $1(0.0)$ \\
\hline \multicolumn{4}{|l|}{ Ethnicity, n (\%) } \\
\hline Caucasian & $46(41.8)$ & $50(44.3)$ & $96(43.1)$ \\
\hline Non-Caucasian & $64(58.2)$ & $60(53.0)$ & $124(55.6)$ \\
\hline Refuse to answer & $0(0.0)$ & $2(1.8)$ & $2(0.9)$ \\
\hline \multicolumn{4}{|l|}{ Education, n (\%) } \\
\hline High school or less & $32(29.1)$ & $37(32.7)$ & $69(31.0)$ \\
\hline College degree or diploma & $49(46.6)$ & $44(38.9)$ & $93(41.7)$ \\
\hline Undergraduate university degree & $11(10.0)$ & $14(12.4)$ & $25(11.2)$ \\
\hline Postgraduate degree & $5(4.6)$ & $6(5.3)$ & $11(5.0)$ \\
\hline Other & $4(3.6)$ & $8(7.1)$ & $12(5.3)$ \\
\hline Not applicable & $2(1.8)$ & $1(0.9)$ & $3(1.3)$ \\
\hline Refuse to answer & $6(5.4)$ & $2(1.8)$ & $8(3.6)$ \\
\hline Missing & $1(0.9)$ & $1(0.9)$ & $2(0.9)$ \\
\hline$\$ 35,000-\$ 50,000$ & $10(9.1)$ & $24(21.2)$ & $34(15.1)$ \\
\hline$>\$ 50,000-\$ 80,000$ & $23(20.9)$ & $17(15.0)$ & $40(18.0)$ \\
\hline$>\$ 80,000-\$ 150,000$ & $17(15.5)$ & $21(18.6)$ & $38(17.0)$ \\
\hline$>\$ 150,000$ & $6(5.5)$ & $5(4.4)$ & $11(5.0)$ \\
\hline Not applicable & $9(8.2)$ & $4(3.5)$ & $13(5.8)$ \\
\hline Refuse to answer & $15(13.6)$ & $16(14.2)$ & $31(13.9)$ \\
\hline Missing & $0(0.0)$ & $2(1.8)$ & $2(0.9)$ \\
\hline \multicolumn{4}{|l|}{ Time since diabetes diagnosis, $\mathbf{n}(\%)$} \\
\hline 0-6 months & $16(14.6)$ & $24(21.2)$ & $40(18)$ \\
\hline$>6$ months to 2 years & $25(22.7)$ & $27(23.9)$ & $52(23)$ \\
\hline$>2-5$ years & $26(23.6)$ & $13(11.5)$ & $39(18)$ \\
\hline $5+$ years & $41(37.3)$ & $47(41.6)$ & $88(40)$ \\
\hline Unsure & $1(0.9)$ & $2(1.8)$ & $3(1)$ \\
\hline Missing & $1(0.9)$ & $0(0.0)$ & $1(0.0)$ \\
\hline Baseline value for $\mathrm{HbA}_{1 \mathrm{c}}{ }^{\mathrm{b}}$, mean (SD) & $8.89(1.82)$ & $9.03(1.53)$ & $8.96(1.68)$ \\
\hline \multicolumn{4}{|l|}{ Time in diabetes education, $n(\%)$} \\
\hline New patient & $35(31.8)$ & $41(363)$ & $76(34.1)$ \\
\hline 1-6 months & $15(13.6)$ & $22(19.5)$ & $37(16.6)$ \\
\hline$>6-12$ months & $22(20.0)$ & $19(16.8)$ & $41(18.4)$ \\
\hline
\end{tabular}




\begin{tabular}{llll}
\hline Variable & Immediate treatment group $(\mathrm{n}=110), \mathrm{n}(\%)$ & Wait-list control $(\mathrm{n}=113), \mathrm{n}(\%)$ & Overall $(\mathrm{N}=223), \mathrm{n}(\%)$ \\
\hline Unsure & $1(0.9)$ & $0(0)$ & $1(0.4)$ \\
Missing & $1(0.9)$ & $0(0)$ & $1(0.4)$ \\
Insulin use, $\mathbf{n}(\%)$ & & & $110(49.0)$ \\
Yes & $50(45.0)$ & $60(53.0)$ & $113(51.0)$ \\
No & $60(55.0)$ & $53(47.0)$ & \\
\hline
\end{tabular}

${ }^{\mathrm{a}} \mathrm{N}=222$.

${ }^{b} \mathrm{HbA}_{1 \mathrm{c}}$ : hemoglobin $\mathrm{A}_{1 \mathrm{c}}, \mathrm{N}=172$.

Table 1 summarizes the demographic characteristics of the study population. There were no significant differences in patient characteristics including age, gender, ethnicity, education, and household income. About 18.0\% (40/223) of participants were diagnosed with T2DM within the last 6 months, whereas $39.5 \%$ $(88 / 223)$ had a diagnosis of T2DM for over 5 years. The average $\mathrm{HbA}_{1 \mathrm{c}}$ level for the study population was $8.96 \%$ (SD 1.68) and was similar between the 2 study arms, and the use of insulin was similar between the 2 groups. Additional clinical features, including baseline medication usage and comorbidities, were similar across study arms (Multimedia Appendix 3).

\section{Outcomes}

\section{Primary Outcome}

Figure 2 shows the $\mathrm{HbA}_{1 \mathrm{c}}$ levels for patients in the ITG and WLC group at baseline, 3 months, and 6 months. At 3 months, the unadjusted mean $\mathrm{HbA}_{1 \mathrm{c}}$ values were $8.22 \%$ for the ITG and $8.41 \%$ for the WLC group. The results of an ANCOVA controlling for baseline values of 120 participants (63 WLC and 57 ITG) did not show evidence of impact on $\mathrm{HbA}_{1 \mathrm{c}}$ levels at 3 months for those in the ITG (mean difference [ITG-WLC] $-0.42,95 \% \mathrm{CI}-1.05$ to $0.21 ; P=.19)$. This nonsignificant difference between groups persisted after adjustment for study site, length of diabetes diagnosis, ethnicity, and length of time spent in the DEP (mean difference [ITG-WLC] $-0.12,95 \%$ CI -0.71 to 0.47$)$.

Baseline characteristics were compared between the 120 participants included in the above model with the 103 participants who had incomplete $\mathrm{HbA}_{1 \mathrm{c}}$ data and were excluded to determine whether the 2 subgroups differed systematically from one another. After adjusting the main ANCOVA model for all covariates found to be associated with complete versus

incomplete $\mathrm{HbA}_{1 \mathrm{c}}$ data (ie, site, time since diabetes diagnosis, ethnicity, antidepressant use, dyslipidemia, and obesity), the effect of treatment on 3-month $\mathrm{HbA}_{1 \mathrm{c}}$ levels remained statistically insignificant (least squares adjusted mean difference $-0.33,95 \%$ CI -0.99 to 0.34$)$.

An exploratory analysis of ITG participants investigating the impact of app usage on 3-month $\mathrm{HbA}_{1 \mathrm{c}}$ levels while adjusting for baseline $\mathrm{HbA}_{1 \mathrm{c}}$ levels was conducted using an ANCOVA. Only 57 participants were complete cases and included in the regression. Each additional day of app use corresponded with a 0.016-point decrease in participant's 3-month $\mathrm{HbA}_{1 \mathrm{c}}$ levels (95\% CI -0.03 to $-0.003 ; P=.02$ ). In other words, 25 days of additional use of the app corresponded with an $\mathrm{HbA}_{1 \mathrm{c}}$ reduction of $0.4 \%$. A correlation matrix of this analysis (Multimedia Appendix 4) found a weak correlation between increased use of the exercise feature with lower $\mathrm{HbA}_{1 \mathrm{c}}$ levels at 3 months $\left(\rho_{\mathrm{s}}=-0.33 ; P=.01\right)$. An analysis of ITG participants, using a paired $t$ test, did not show a statistically significant difference in $\mathrm{HbA}_{1 \mathrm{c}}$ levels between 3 and 6 months (mean difference 0.16, $95 \%$ CI -0.48 to 0.81 ).

\section{Secondary Outcomes}

Overall, there was no difference in patient-reported diabetes self-care behaviors (measured by PAID and Summary of Diabetes Self-Care Activities-6) or general health status (measured by EQ-5D) at 3 months between intervention arms in both the unadjusted and adjusted models (Multimedia Appendix 5). Furthermore, there was no difference in health care utilization at 3 months between groups (Table 2). An exploratory analysis of 63 ITG participants investigating the impact of app usage on PAID score levels at 3 months, adjusting for baseline scores, did not show evidence of significance $(95 \%$ CI -0.28 to $0.091 ; P=.32$ ). 
Figure 2. Mean $\mathrm{HbA}_{1 \mathrm{c}}$ (hemoglobin $\mathrm{A}_{1 \mathrm{c}}$ ) values for intervention and control groups from baseline to 6 months.

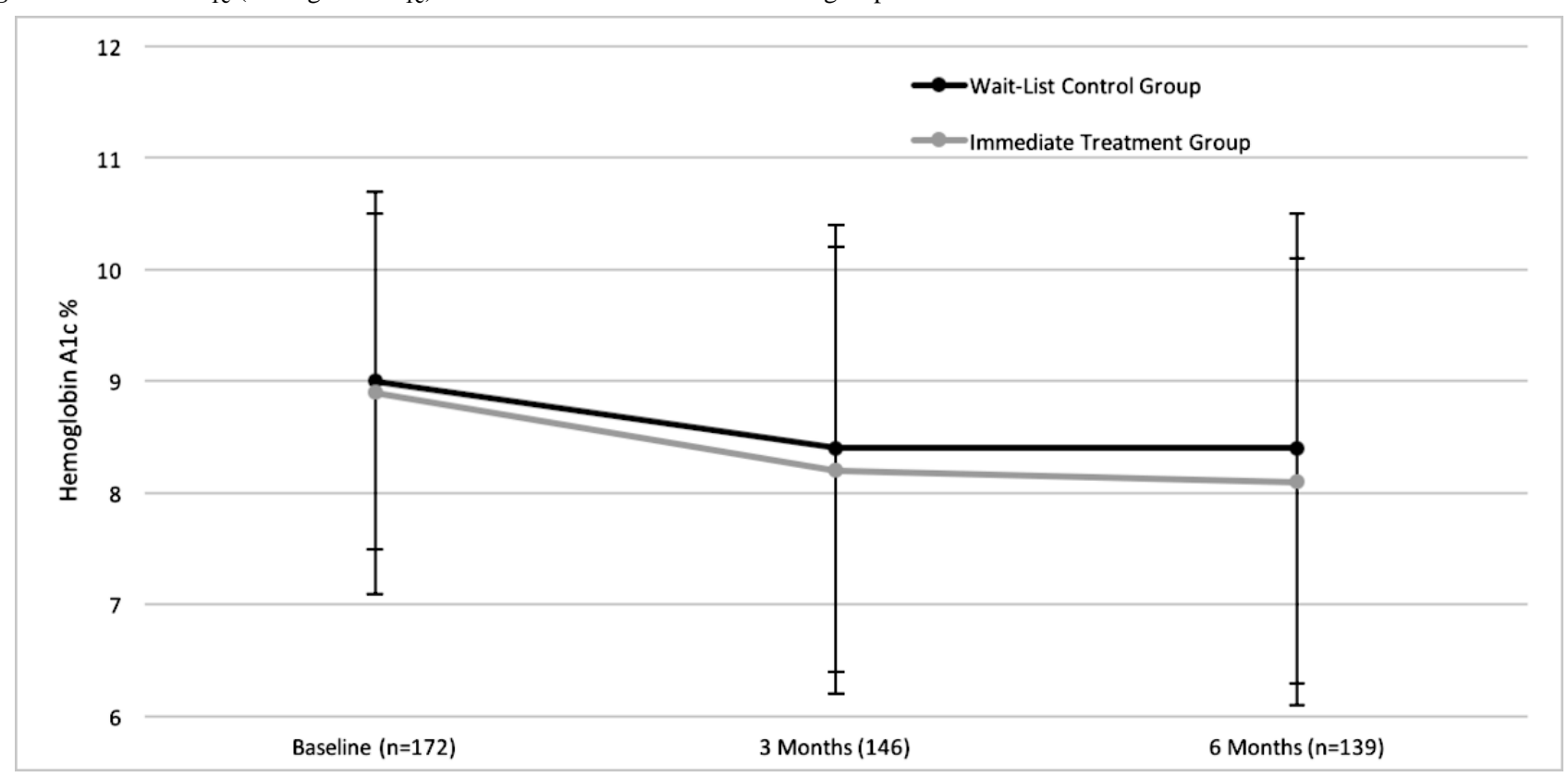

Table 2. Health service utilization.

\begin{tabular}{|c|c|c|c|c|c|c|}
\hline \multirow[t]{2}{*}{ Outcome ( $\mathrm{N}=$ baseline/3 month) } & \multicolumn{2}{|c|}{$\mathrm{ITG}^{\mathrm{a}}(\%$ with event $)$} & \multicolumn{2}{|c|}{$\mathrm{WLC}^{\mathrm{b}}(\%$ with event) } & \multirow[t]{2}{*}{ Odds ratio $(95 \% \mathrm{CI})$} & \multirow[t]{2}{*}{$P$ value } \\
\hline & Baseline, n (\%) & 3 months, $\mathrm{n}(\%)$ & Baseline, n (\%) & 3 months, $\mathrm{n}(\%)$ & & \\
\hline Emergency deparment visits (223/139) & $21(19.0)$ & $5(7.5)$ & $12(10.6)$ & $5(6.8)$ & $1.11(0.03-0.18)$ & 0.86 \\
\hline Hypoglycemic episodes (223/139) & $32(29.0)$ & $21(31.8)$ & $25(22.1)$ & $15(20.5)$ & $1.80(0.84-3.89)$ & 0.13 \\
\hline Hospital admission (223/139) & $23(20.9)$ & $9(13.6)$ & $16(14.1)$ & $4(5.4)$ & $2.72(0.78-9.91)$ & 0.11 \\
\hline Visit to primary care provider $(222 / 138)$ & $95(86.3)$ & $57(86.3)$ & $103(91.1)$ & $64(87.6)$ & $0.79(0.29-2.19)$ & 0.65 \\
\hline Visit to specialist (223/139) & $78(70.9)$ & $37(56.0)$ & $70(61.9)$ & $46(63.0)$ & $0.75(0.38-1.48)$ & 0.40 \\
\hline
\end{tabular}

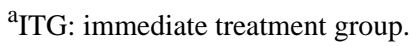

${ }^{b}$ WLC: wait-list control.

\section{Mobile App Utilization and Satisfaction}

Overall, there was low app utilization among ITG participants with a mean number of log-in days of 42.4 (SD 52.1) over 26 weeks, of which $46.4 \%$ (51/110) of participants used the app for 10 days or less. There was a small percentage of high users, with $18.2 \%$ (20/110) of participants using the app 100 days or more over a 182-day period. Multimedia Appendix 6 shows average number of log-in days among ITG participants over 26 weeks, showing significant decreasing mean usage over time. Blood glucose tracking was the most utilized feature with an average of 76.6 entries over 14 weeks (SD 96.59), whereas exercise tracking was the least utilized (mean 26.7 [SD 53.4]; see Figure 3). Of note, this graph also shows high variability in usage by site. Over the first 14 weeks, site 2 showed the highest number of log-in days by participants (median 36 ; interquartile range [IQR] 10.5-124), whereas participants from site 3 used the app significantly less (median 9; IQR 6-51). Site 1 has intermediate usage (median 17; IQR 7-72). Users with a diagnosis of diabetes in the last 6 months were the most engaged as assessed by days of log-in (median 24.5; IQR 8.7-73.5), whereas those with a diagnosis for over 5 years also had high engagement (median 18; IQR 8-86).

User ratings were completed by 105 participants to assess satisfaction with the app. Almost half of those who responded (45.7, 48/105) stated they would recommend the app to all people like them. Moreover, $41.0 \%$ (43/105) stated they would use the app 50 times or more if they continued to have access to it. About half $(53.3 \%, 56 / 105)$ gave the app a rating of 4 to 5 stars of 5 , whereas $39.0 \%(41 / 105)$ gave the app a rating of 3 stars. When asked if they would be willing to pay for the app, the majority of participants $(55.2 \%, 58 / 105)$ stated they would not. 
Figure 3. Mean number of observations recorded by feature and site for immediate treatment group (ITG) participants over 14 weeks.

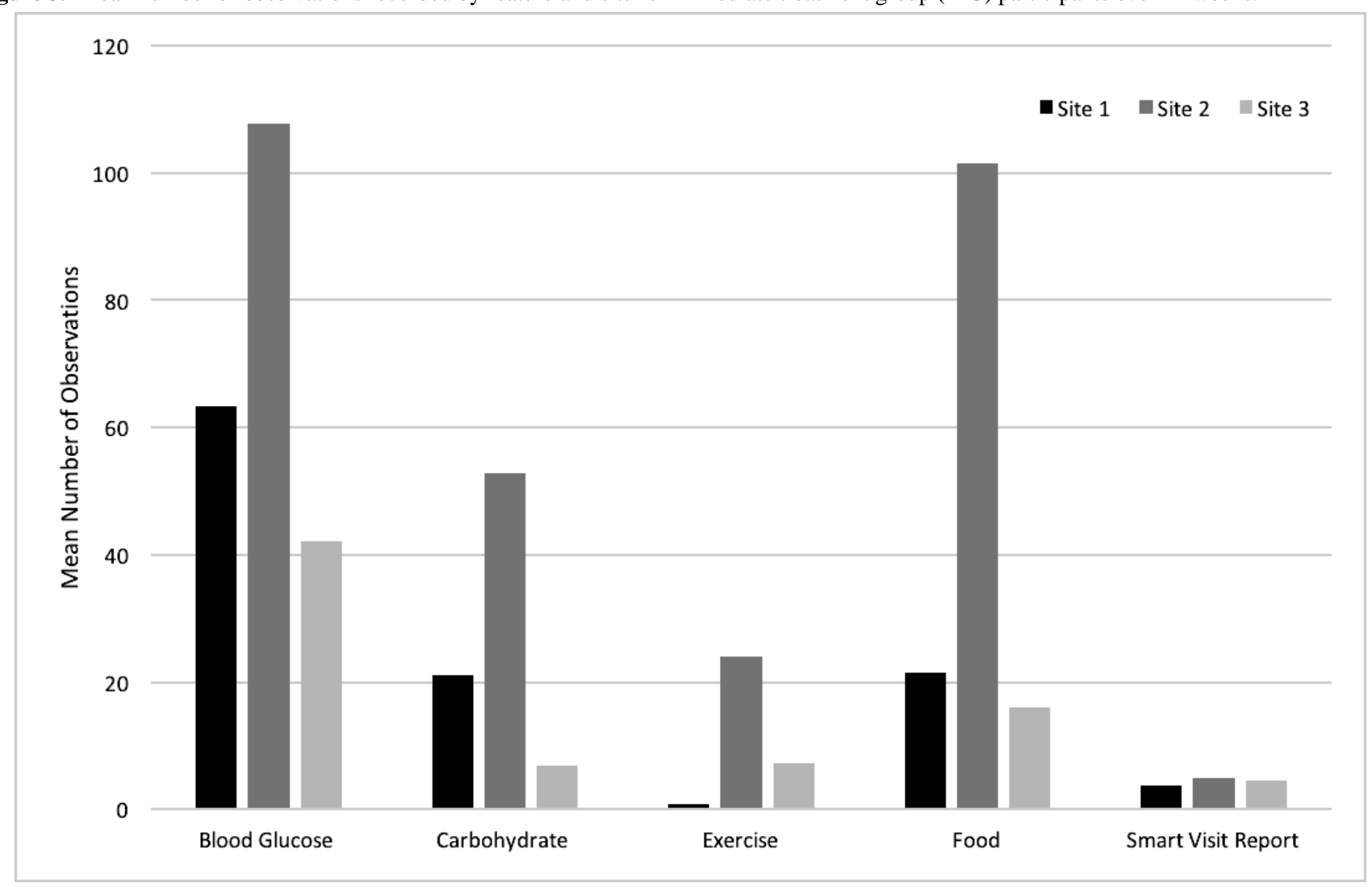

\section{Discussion}

\section{Principal Findings}

The aim of this study was to evaluate the clinical impact of the BlueStar app for diabetes self-management in a real-world multisite implementation. The results showed no difference between intervention and control arms for the primary clinical outcome of glycemic control as measured by $\mathrm{HbA}_{1 \mathrm{c}}$. Furthermore, we found no intervention effect on secondary outcomes measuring diabetes self-efficacy, quality of life, and health care utilization behaviors. Of note, there was relative low use of the app overall, with almost half of intervention group users having minimal engagement with the app. Many app features were poorly utilized, including diet and exercise tracking, which have previously shown to play an important role in T2DM self-management [10]. There was a small number of highly engaged users, and exploratory analysis suggests a correlation with app usage, and improvement in $\mathrm{HbA}_{1 \mathrm{c}}$ levels at 3 months analysis suggests that 25 days of usage associated with an improvement in $\mathrm{HbA}_{1 \mathrm{c}}$ level by $0.4 \%$, a clinically significant change [24].

To our knowledge, this is the largest pragmatic multisite trial of evaluation of a mobile app for self-management of T2DM, and the results are in contrast to prior published studies of mobile app for diabetes self-management. These studies of mobile apps for T2DM largely consist of small single-site studies with a homogeneous population [8,25]. A meta-analysis of 10 studies of T2DM apps reported a medium reduction in $\mathrm{HbA}_{1 \mathrm{c}}$ level of $0.55 \%$ among those using an app, with all studies reporting some positive benefit. However, these tended to have small study populations, and 8 of the 10 studies included additional ongoing feedback from the PCP as part of the intervention [8]. Similarly, a previous study of the same mobile app, which showed significant decrease in $\mathrm{HbA}_{1 \mathrm{c}}$ level among intervention participants, was conducted with only 30 participants. Moreover, in that study, the intervention arm received the mobile app plus multiple follow-up interactions from the research team to the physician and patient [13]. This large multisite study likely represents a more realistic assessment of impact for a diabetes health app across a health system than smaller, higher touch, single-site studies.

Our findings suggest that when evaluating a mobile app for chronic disease management, it is important to ask not only if the app works but also in what context, for which patients, and how to promote ongoing engagement of use. Overall, there was low usage of the app among participants. However, results indicate that contextual factors, particularly site, had a significant impact on overall usage of the app. App usage overall and across features was almost twice as high among site 2 compared with site 3. Despite comprehensive implementation protocols, there were substantial differences in time spent training clinicians, time training patients, and ongoing engagement with patients between clinical test sites, with the highest use site spending the greatest time and resources on implementation. In addition, it is increasingly evident that digital health apps designed to improve chronic disease self-management require ongoing patient engagement as a key determinant of clinical impact [26-30]. Therefore, a successful implementation and evaluation of these apps require careful consideration of factors that impact patient app utilization [30]. In this study, patients with a new diagnosis of T2DM had 
significantly higher usage than those who were diagnosed more than 6 months prior. Previous studies have shown patient factors including age, internal motivation, and personal values impact utilization of mobile health technologies [31]. This aligns with the results of a qualitative evaluation conducted with a subset of patients from this study. It found that perceived self-efficacy, competing priorities, and beliefs about the usefulness of virtual solutions had a significant impact on app utilization [17].

A recent systematic review of factors that impact engagement with digital health interventions highlighted the importance of both patient factors and engagement and recruitment methods [32]. Several recent studies of apps for T2DM have emphasized the importance of an implementation that includes a strong clinical endorsement and ongoing clinical support to increase overall usage [33,34]. A qualitative study of patients who dropped out of a study evaluating a self-management app for T2DM cited lack of clinician support as the primary reason for leaving. Our complementary qualitative study found participants with high app utilization identified the health care provider and/or site coordinator as a significant source of support in app adoption. These align with our quantitative findings that variation in app usage across sites was at least in part driven by variation in implementation. Future implementations of digital health apps would benefit from a clear effort to include factors that improve engagement, including a strong clinical endorsement, ongoing physician involvement, and patient reminders [35].

\section{Limitations}

Several limitations to this study warrant discussion. Importantly, the study was underpowered to detect small but potentially still important differences in $\mathrm{HbA}_{1 \mathrm{c}}$ levels. The studies' high dropout rate of $34.5 \%$ (77/223), while in line with prior electronic health (eHealth) studies, may have led to an underestimation of the clinical impact among participants [36,37]. There were several study design factors that likely contributed to the low app usage and lack of a detected intervention effect. Instead of downloading the app, participants were given the intervention on a second phone they used for the duration of the study in an attempt to standardize implementation by the funder. However, the use of a second phone to deliver eHealth interventions has been a noted barrier to usage in previous studies, and future mobile app evaluations would likely benefit from allowing participants to use their own smartphones when possible [28]. Given previous evidence on the benefits of strong primary care participation in diabetes self-management apps, the use of DEPs as the primary site of recruitment likely had a negative impact on enrollment, usage, and clinical impact [38,39]. Clinicians at the selected DEPs did not have regular communication with PCPs, and therefore, there was no robust pathway to report use of the app or possible treatment enhancements to the PCP. Future implementations of this, or similar apps, would likely benefit from strong primary care involvement throughout the study who can support self-management through direct treatment changes including medication titration. Finally, as discussed previously, significant variations in implementation across sites likely also had significant impact on site usage and overall ability to detect a clinical effect.

\section{Conclusions}

In this large real-world evaluation of a mobile app for diabetes self-management, we found no significant difference in $\mathrm{HbA}_{1 \mathrm{c}}$ levels between the intervention and control groups. Future research into the patient and site-specific factors that would increase app utilization would be warranted.

\section{Acknowledgments}

The research team would like to acknowledge Susan Franchi and Lorrie McKevitt (St. Joseph Care Group, Thunder Bay); Kevin Edwards, Ana Offenheim, and Richard Hundert (North York General Hospital); and Tina Parmar and Zita Maingi-Michire (William Osler Health System), as well as the site leads, project coordinators, and research assistants for their roles in project planning, recruitment, and data collection.

\section{Conflicts of Interest}

PA received a stipend to work on a project, unrelated to this study, from the Ontario Telemedicine Network who partially supported this evaluation. NMI received an honorarium to act as cochair of the Dissemination and Implementation Committee for the national guidelines developed by Diabetes Canada.

\section{Multimedia Appendix 1}

BlueStar mobile app interface.

[PDF File (Adobe PDF File), 363KB-Multimedia Appendix 1]

\section{Multimedia Appendix 2}

Comparison of baseline characteristics among those with and without an $\mathrm{HbA}_{1 \mathrm{c}}$ (hemoglobin $\mathrm{A}_{1 \mathrm{c}}$ ) value at 3 months.

\section{[PDF File (Adobe PDF File), 35KB-Multimedia Appendix 2]}

\section{Multimedia Appendix 3}

Baseline clinical characteristics of participants. 
[PDF File (Adobe PDF File), 27KB-Multimedia Appendix 3]

\section{Multimedia Appendix 4}

Spearman correlation coefficients of immediate treatment group (ITG) participants with complete cases $(n=57)$.

[PDF File (Adobe PDF File), 29KB-Multimedia Appendix 4]

\section{Multimedia Appendix 5}

Patient-reported outcome and experience measures.

[PDF File (Adobe PDF File), 29KB-Multimedia Appendix 5]

\section{Multimedia Appendix 6}

Mean app usage among immediate treatment group (ITG) users over time.

[PNG File, 31KB-Multimedia Appendix 6]

\section{Multimedia Appendix 7}

CONSORT - EHEALTH checklist (V.1.6.1).

[PDF File (Adobe PDF File), 2MB-Multimedia Appendix 7]

\section{References}

1. Guariguata L, Whiting DR, Hambleton I, Beagley J, Linnenkamp U, Shaw JE. Global estimates of diabetes prevalence for 2013 and projections for 2035. Diabetes Res Clin Pract 2014 Feb;103(2):137-149. [doi: 10.1016/j.diabres.2013.11.002]

[Medline: 24630390]

2. Norris S, Lau J, Smith SJ, Schmid CH, Engelgau MM. Self-management education for adults with type 2 diabetes: a meta-analysis of the effect on glycemic control. Diabetes Care 2002 Jul;25(7):1159-1171. [Medline: 12087014 ]

3. Gaede P, Lund-Andersen H, Parving HH, Pedersen O. Effect of a multifactorial intervention on mortality in type 2 diabetes. N Engl J Med 2008 Feb 07;358(6):580-591. [doi: 10.1056/NEJMoa0706245] [Medline: 18256393]

4. Powers M, Bardsley J, Cypress M, Duker P, Funnell MM, Fischl AH, et al. Diabetes self-management education and support in type 2 diabetes: a joint position statement of the American Diabetes Association, the American Association of Diabetes Educators, and the Academy of Nutrition and Dietetics. Clin Diabetes 2016 Apr;34(2):70-80 [FREE Full text] [doi: 10.2337/diaclin.34.2.70] [Medline: 27092016]

5. Worswick J, Wayne SC, Bennett R, Fiander M, Mayhew A, Weir MC, et al. Improving quality of care for persons with diabetes: an overview of systematic reviews - what does the evidence tell us? Syst Rev 2013 May 07;2:26 [FREE Full text] [doi: 10.1186/2046-4053-2-26] [Medline: 23647654]

6. Fitzner K, Moss G. Telehealth--an effective delivery method for diabetes self-management education? Popul Health Manag 2013 Jun;16(3):169-177. [doi: 10.1089/pop.2012.0054] [Medline: 23216062]

7. Pal K, Eastwood SV, Michie S, Farmer AJ, Barnard ML, Peacock R, et al. Computer-based diabetes self-management interventions for adults with type 2 diabetes mellitus. Cochrane Database Syst Rev 2013;3:CD008776. [doi: 10.1002/14651858.CD008776.pub2] [Medline: 23543567]

8. Hou C, Carter B, Hewitt J, Francisa T, Mayor S. Do mobile phone applications improve glycemic control (HbA1c) in the self-management of diabetes? A systematic review, meta-analysis, and GRADE of 14 randomized trials. Diabetes Care 2016 Dec;39(11):2089-2095. [doi: 10.2337/dc16-0346] [Medline: 27926892]

9. Saffari M, Ghanizadeh G, Koenig HG. Health education via mobile text messaging for glycemic control in adults with type 2 diabetes: a systematic review and meta-analysis. Prim Care Diabetes 2014 Dec;8(4):275-285. [doi:

10.1016/j.pcd.2014.03.004] [Medline: 24793589]

10. Årsand E, Frøisland DH, Skrøvseth SO, Chomutare T, Tatara N, Hartvigsen G, et al. Mobile health applications to assist patients with diabetes: lessons learned and design implications. J Diabetes Sci Technol 2012 Sep 01;6(5):1197-1206 [FREE Full text] [doi: 10.1177/193229681200600525] [Medline: 23063047]

11. Bovbjerg M, Lee J, Wolff R, Bangs B, May MA. Pilot study for managing complex chronic care medicaid patients with diabetes using a mobile health application achieves "Triple Aim" improvement in a primary care setting. Clin Diabetes 2017 Oct;35(4):227-231 [FRE Full text] [doi: 10.2337/cd17-0006] [Medline: 29109612]

12. Whitehead L, Seaton P. The effectiveness of self-management mobile phone and tablet apps in long-term condition management: a systematic review. J Med Internet Res 2016 May 16;18(5):e97 [FREE Full text] [doi: 10.2196/jmir.4883] [Medline: 27185295] 
13. Quinn C, Clough SS, Minor JM, Lender D, Okafor MC, Gruber-Baldini A. WellDoc mobile diabetes management randomized controlled trial: change in clinical and behavioral outcomes and patient and physician satisfaction. Diabetes Technol Ther 2008 Jun;10(3):160-168. [doi: 10.1089/dia.2008.0283] [Medline: 18473689]

14. Waltz E. IEEE Spectrum (2014). BlueStar, the Frist Prescription-Only App URL: https://spectrum.ieee.org/biomedical/ devices/bluestar-the-first-prescriptiononly-app [accessed 2018-11-12] [WebCite Cache ID 73sd2hKA7]

15. Gude W, van der Veer SN, de Keizer NF, Coiera E, Peek N. Optimizing digital health informatics interventions through unobtrusive quantitative process evaluations. Stud Health Technol Inform 2016;228:594-598. [Medline: 27577453]

16. Siminerio L, Ruppert KM, Gabbay RA. Who can provide diabetes self-management support in primary care? Findings from a randomized controlled trial. Diabetes Educ 2013;39(5):705-713. [doi: 10.1177/0145721713492570] [Medline: 23782622]

17. Desveaux L, Agarwal P, Shaw J, Hensel JM, Mukerji G, Onabajo N, et al. A randomized wait-list control trial to evaluate the impact of a mobile application to improve self-management of individuals with type 2 diabetes: a study protocol. BMC Med Inform Decis Mak 2016 Dec 15;16(1):144 [FREE Full text] [doi: 10.1186/s12911-016-0381-5] [Medline: 27842539]

18. Harris P, Taylor R, Thielke R, Payne J, Gonzalez N, Conde JG. Research electronic data capture (REDCap)--a metadata-driven methodology and workflow process for providing translational research informatics support. J Biomed Inform 2009 Apr;42(2):377-381 [FREE Full text] [doi: 10.1016/j.jbi.2008.08.010] [Medline: 18929686]

19. American Association of Diabetes Educators. 2010. AADE7 Self-Care Behaviors URL: https://www.diabeteseducator.org/ living-with-diabetes/aade7-self-care-behaviors [accessed 2018-11-12] [WebCite Cache ID 73sdJ7610]

20. Thorpe K, Zwarenstein M, Oxman AD, Treweek S, Furberg CD, Altman DG, et al. A pragmatic-explanatory continuum indicator summary (PRECIS): a tool to help trial designers. J Clin Epidemiol 2009 May;62(5):464-475. [doi: 10.1016/i.jclinepi.2008.12.011] [Medline: 19348971$]$

21. Welch G, Jacobson AM, Polonsky WH. The problem areas in diabetes scale. An evaluation of its clinical utility. Diabetes Care 1997 May;20(5):760-766. [Medline: 9135939]

22. Toobert D, Hampson SE, Glasgow RE. The summary of diabetes self-care activities measure: results from 7 studies and a revised scale. Diabetes Care 2000 Jul;23(7):943-950 [FREE Full text] [Medline: 10895844]

23. Herdman M, Gudex C, Lloyd A, Janssen M, Kind P, Parkin D, et al. Development and preliminary testing of the new five-level version of EQ-5D (EQ-5D-5L). Qual Life Res 2011 Dec;20(10):1727-1736 [FREE Full text] [doi: 10.1007/s11136-011-9903-x] [Medline: 21479777]

24. Food and Drug Administration. U.S. Department of Health and Human Services. 2008. Diabetes Mellitus: Developing Drugs and Therapeutic Biologics for Treatment and Prevention URL: https://www.fda.gov/downloads/Drugs/.../Guidances/ ucm071624.pdf [accessed 2018-11-12] [WebCite Cache ID 73sdr2g3t]

25. McMillan K, Kirk A, Hewitt A, MacRury S. A systematic and integrated review of mobile-based technology to promote active lifestyles in people with type 2 diabetes. J Diabetes Sci Technol 2017 Dec;11(2):299-307 [FREE Full text] [doi: 10.1177/1932296816656018] [Medline: 27334301]

26. Hartin P, Nugent CD, McClean SI, Cleland I, Tschanz JT, Clark CJ, et al. The empowering role of mobile apps in behavior change interventions: the gray matters randomized controlled trial. JMIR Mhealth Uhealth 2016 Aug 02;4(3):e93 [FREE Full text] [doi: 10.2196/mhealth.4878] [Medline: 27485822]

27. Morrison L, Hargood C, Lin SX, Dennison L, Joseph J, Hughes S, et al. Understanding usage of a hybrid website and smartphone app for weight management: a mixed-methods study. J Med Internet Res 2014 Oct 22;16(10):e201 [FREE Full text] [doi: 10.2196/jmir.3579] [Medline: 25355131]

28. Goyal S, Nunn CA, Rotondi M, Couperthwaite AB, Reiser S, Simone A, et al. A mobile app for the self-management of type 1 diabetes among adolescents: a randomized controlled trial. JMIR Mhealth Uhealth 2017 Jun 19;5(6):e82 [FREE Full text] [doi: 10.2196/mhealth.7336] [Medline: 28630037]

29. Andrews S, Sperber NR, Gierisch JM, Danus S, Macy SL, Bosworth HB, et al. Patient perceptions of a comprehensive telemedicine intervention to address persistent poorly controlled diabetes. Patient Prefer Adherence 2017;11:469-478 [FREE Full text] [doi: 10.2147/PPA.S125673] [Medline: 28424543]

30. Alvarado M, Kum HC, Gonzalez Coronado K, Foster MJ, Ortega P, Lawley MA. Barriers to remote health interventions for type 2 diabetes: a systematic review and proposed classification scheme. J Med Internet Res 2017 Dec 13;19(2):e28 [FREE Full text] [doi: 10.2196/jmir.6382] [Medline: 28193598]

31. Scott A, Alore EA, Naik AD, Berger DH, Suliburk JW. Mixed-methods analysis of factors impacting use of a postoperative mHealth app. JMIR Mhealth Uhealth 2017 Feb 08;5(2):e11 [FRE Full text] [doi: 10.2196/mhealth.6728] [Medline: 28179215]

32. O'Connor S, Hanlon P, O'Donnell CA, Garcia S, Glanville J, Mair FS. Understanding factors affecting patient and public engagement and recruitment to digital health interventions: a systematic review of qualitative studies. BMC Med Inform Decis Mak 2016 Dec 15;16(1):120 [FREE Full text] [doi: 10.1186/s12911-016-0359-3] [Medline: 27630020]

33. Lie S, Karlsen B, Oord ER, Graue M, Oftedal B. Dropout from an eHealth intervention for adults with type 2 diabetes: a qualitative study. J Med Internet Res 2017 May 30;19(5):e187 [FREE Full text] [doi: 10.2196/jmir.7479] [Medline: 28559223] 
34. Cui M, Wu X, Mao J, Wang X, Nie M. T2DM self-management via smartphone applications: a systematic review and meta-analysis. PLoS One 2016;11(11):e0166718 [FREE Full text] [doi: 10.1371/journal.pone.0166718] [Medline: 27861583]

35. Attwood S, Morton KL, Mitchell J, Van Emmenis M, Sutton S, VBI Programme Team. Reasons for non-participation in a primary care-based physical activity trial: a qualitative study. BMJ Open 2016 Dec 23;6(5):e011577 [FREE Full text] [doi: 10.1136/bmjopen-2016-011577] [Medline: 27217288]

36. Eysenbach G. The law of attrition. J Med Internet Res 2005 Mar 31;7(1):e11 [FREE Full text] [doi: 10.2196/jmir.7.1.e11] [Medline: 15829473]

37. Donkin L, Christensen H, Naismith SL, Neal B, Hickie IB, Glozier N. A systematic review of the impact of adherence on the effectiveness of e-therapies. J Med Internet Res 2011 Aug 05;13(3):e52 [FREE Full text] [doi: 10.2196/jmir.1772] [Medline: 21821503]

38. Chomutare T, Fernandez-Luque L, Arsand E, Hartvigsen G. Features of mobile diabetes applications: review of the literature and analysis of current applications compared against evidence-based guidelines. J Med Internet Res 2011 Sep 22;13(3):e65 [FREE Full text] [doi: 10.2196/jmir.1874] [Medline: 21979293]

39. Katz R, Mesfin T, Barr K. Lessons from a community-based mHealth diabetes self-management program: "it's not just about the cell phone". J Health Commun 2012;17(Suppl 1):67-72. [doi: 10.1080/10810730.2012.650613] [Medline: 22548601]

\author{
Abbreviations \\ AHRC: Applied Health Research Centre \\ ANCOVA: analysis of covariance \\ DEP: diabetes education program \\ eHealth: electronic health \\ EQ-5D: EuroQol-5D \\ HbA $_{1 \mathbf{c}}$ : hemoglobin $\mathrm{A}_{1 \mathrm{c}}$ \\ IQR: interquartile range \\ ITG: immediate treatment group \\ OHIP: Ontario Health Insurance Program \\ PAID: Problem Areas in Diabetes \\ PCP: primary care provider \\ T2DM: type 2 diabetes mellitus \\ WLC: wait-list control
}

\author{
Edited by G Eysenbach; submitted 06.03.18; peer-reviewed by C Mamillapalli, L Berard, A Gilani; comments to author 17.07.18; \\ revised version received 08.09.18; accepted 14.09.18; published 10.01.19 \\ Please cite as: \\ Agarwal P, Mukerji G, Desveaux L, Ivers NM, Bhattacharyya O, Hensel JM, Shaw J, Bouck Z, Jamieson T, Onabajo N, Cooper M, \\ Marani H, Jeffs L, Bhatia RS \\ Mobile App for Improved Self-Management of Type 2 Diabetes: Multicenter Pragmatic Randomized Controlled Trial \\ JMIR Mhealth Uhealth 2019;7(1):e10321 \\ URL: https://mhealth.jmir.org/2019/1/e10321/ \\ doi: $\underline{10.2196 / 10321}$ \\ PMID: 30632972
}

CPayal Agarwal, Geetha Mukerji, Laura Desveaux, Noah M Ivers, Onil Bhattacharyya, Jennifer M Hensel, James Shaw, Zachary Bouck, Trevor Jamieson, Nike Onabajo, Madeline Cooper, Husayn Marani, Lianne Jeffs, R Sacha Bhatia. Originally published in JMIR Mhealth and Uhealth (http://mhealth.jmir.org), 10.01.2019. This is an open-access article distributed under the terms of the Creative Commons Attribution License (https://creativecommons.org/licenses/by/4.0/), which permits unrestricted use, distribution, and reproduction in any medium, provided the original work, first published in JMIR mhealth and uhealth, is properly cited. The complete bibliographic information, a link to the original publication on http://mhealth.jmir.org/, as well as this copyright and license information must be included. 